\title{
METODE DAKWAH DALAM PENGAJARAN NABI PERSPEKTIF HADIS
}

\author{
Adi Abdullah Muslim \\ Dosen IAIN Pekalongan, Indonesia \\ Email: adi.abdullah.muslim@iainpekalongan.ac.id
}

\begin{abstract}
This article was inspired by the book of al-Rasul al-Mu'allim by 'Abd al-Fattah Abu Ghuddah. He mentioned that there were about forty classifications of the Prophet's teaching methods as outlined in the form of hadith. The books are written are characterized by forms of educational values. However, in essence the method of education taught by the Prophet was also the way the Prophet conveyed his preaching to his companions. The time of the Prophet who had not yet known communication theories to convey God's messages, gave the results of the formation of strong characters in sahabat Nabi. So what is discussed in this article is about the method of Prophet's preaching in teaching sahabat Nabi the hadith perspective so as to form theories in da'wah communication and education.
\end{abstract}

[Artikel ini terinspirasi dari kitab al-Rasul al-Mu'allim karya 'Abd al-Fattah Abu Ghuddah. Ia menyebutkan bahwa ada sekitar empat puluh klasifikasi metode pengajaran Nabi yang dituangkan dalam bentuk hadis. Buku yang dituliskan banyak diwarnai dengan bentuk nilainilai pendidikan. Namun, pada hakikatnya metode pendidikan yang diajarkan Nabi juga merupakan cara Nabi menyampaikan dakwahnya kepada para sahabat. Di zaman Nabi yang belum dikenal teori-teori komunikasi untuk menyampaikan pesan-pesan Tuhan, memberikan warna dan hasil pembentukan karakter kuat pada diri sahabat. Maka yang dibahas dalam artikel ini mengenai metode dakwah Nabi dalam mengajarkan kepada sahabat perspektif hadis sehingga membentuk teori dalam komunikasi dakwah dan pendidikan].

Kata kunci: metode, nabi, pengajaran, karakter, sahabat

\section{PENDAHULUAN}

Nabi Muhammad merupakan penutup dari para nabi yang diutus oleh Allah di muka bumi sebagai penyempurna syariat dari masa Nabi-nabi sebelum beliau. Keberadaan para Nabi mempunyai dua pondasi dasar dalam menyampaikan da'wah mereka. Pertama, perbaikan akidah serta kedua, pembentukan syariat dan akhlak. Berkenaan dengan akidah, kandungannya tidak pernah berubah sejak diutusnya nabi Adam a.s hingga Nabi terakhir Muhammad saw, mempunyai satu makna, yang berkaitan dengan keesaan Tuhan (Allah) dan kesucian dari segala bentuk yang menyerupai-Nya dengan sifatsifat makhluk, keimanan pada hari akhir, hari penghitungan serta masalah surga dan neraka. Sedangkan syariat yang dimaksud di sini sebagaimana disebutkan oleh Dr. Said Ramadhan al-Buthi dalam bukunya Fiqh al-Sirah yaitu hukum-hukum yang 
mengatur kehidupan dalam bermasyarakat dan personal. Syariat pada saat masa para nabi terdahulu berbeda dengan syariat pada masa Nabi Muhammad saw. Hal ini dikarenakan, syariat mempunyai sifat perkembangan dengan keadaan zaman sebagaimana berbedanya keadaan umat pada masa-masa tertentu. Di mana asas dari pelaksanaan syariat itu sendiri merupakan bentuk kemaslahatan manusia baik di dunia maupun kehidupan setelah kematian. $^{1}$

Sebelum Islam, berbagai macam tradisi telah memiliki kubu-kubunya masing-masing di wilayahnya sendiri, bukan saja dalam tahap tertentu dari kebudayaan dalam seni atau pemerintah dan sebagainya; tetapi juga, sampai taraf di dalam garis-garis komunitas keagamaan tertentu. Dengan datangnya Islam, keseimbangan yang lebih tua diantara tipetipe tradisi telah terganggu dan unsurunsur baru telah diletakkan di sampingnya. Islam sendiri telah meletakkan tradisitradisi baru, yang relatif bebas dari warisan yang lebih tua sekalipun, dengan mana orang-orang harus menyesuaikannya. $^{2}$

${ }^{1}$ Said Ramadhan al-Buthi, Fiqh al-Sirah; Dirasat Manhajiyah 'ilmiyah li Sirat al-Mustafa 'alaihi al-Salah wa al-Salam wa ma yantawi 'alaihi min 'izat wa Mabadi' wa Ahkam, (Damaskus, Dar al-Fikr 1977), hlm. 23-24.

${ }^{2}$ Marshall G. S. Hodgson, The Venture of Islam; Conscience and History in a World Civilization, Vol One: The Classical Age of Islam, (Chicago: Licensed by the University of Chicago Press 1974); Edisi terjemahan, The Venture of
Al-Sirah al-Nabawiyah merupakan catatan sejarah dari Nabi Muhammad saw yang bukan hanya menceritakan sejak lahirnya hingga wafatnya beliau. Akan tetapi, juga sejak sebelum dilahirkan Nabi. ${ }^{3}$ Pertama, kisah yang menceritakan tentang penggalian sumur Zamzam oleh kakek Nabi saw 'Abd Muthalib. Kisah ini diceritakan oleh syaikh Ibrahim al-'Ali dalam bukunya Sahih al-Sirah alNabawiyah. Riwayat ini bersumber dari Ali bin Abi Thalib r.a. ${ }^{4}$ Peristiwa selanjutnya, terbukti dari kisah penyerangan dalam rangka ingin menghancurkan Ka'bah yang dipimpin oleh Raja Abrahah, di mana telah diabadikan kisahnya dalam al-Qur'an ${ }^{5}$ sebagai pelajaran bagi umat manusia untuk

islam; islam dan Sejarah dalam Peradaban Dunia, (Jakarta, Paramadina 2002), hlm. 9.

3 Said Agil Husin al-Munawwar, disampaikan ketika mata kuliah al-Sirah alNabawiyah.

4 Lihat lebih lengkap tentang kisah Penggalian sumur Zamzam oleh 'Abd Muthalib kakek Nabi saw dalam buku karya Dr. 'Ali Muhammad Sallabi, al-Sirah al-Nabawiyah; 'Ardu Waqā'i wa Tahlilu Ahdath, (Kairo, Muassasah Iqra' 2005), hlm. 34.

5 Al-Qur' an Surah al-Fil ayat 1-5

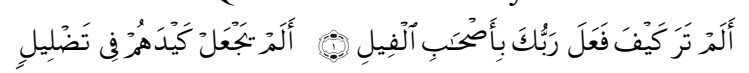

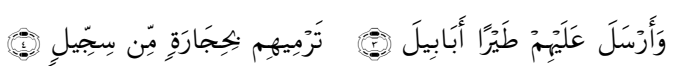

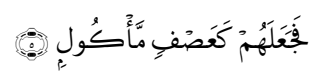

Apakah kamu tidak memperhatikan bagaimana Tuhanmu telah bertindak terhadap tentara bergajah.Bukankah Dia telah menjadikan tipu daya mereka (untuk menghancurkan Ka'bah) itu sia-sia? Dan Dia mengirimkan kapada mereka burung yang berbondong-bondong, yang melempari mereka dengan batu (berasal) dari tanah yang terbakar, lalu Dia menjadikan mereka seperti daun-daun yang dimakan (ulat). 
dijadikan ibrah serta ancaman kepada siapa saja yang ingin menghancurkan Ka'bah di mana merupakan pusat dan simbol umat Islam dalam beribadah khususnya haji yang menjadikan syarat untuk sahnya ibadah dengan menziarahi Masjid al-Haram. Kejadian ini telah ditulis oleh para ahli sejarah pada pembahasan dalam buku sejarah kenabian Muhammad saw.

Setelah masa kelahiran dan perjalanan panjang hidup Nabi, tibalah di mana masa kerasulan, pada saat memasuki tahun ke empat puluh dari umur Nabi saw, yang dimulai dari turunnya wahyu pertama, didahului dengan perintah iqra' (membaca) oleh Allah melalui malaikat Jibril, terdapat banyak hikmah dan esensi yang dapat dipetik bagi umat Nabi Muhammad yang hidup pada masanya serta umat yang hidup setelah beliau wafat. Kedudukan seorang Nabi sebagai sosok manusia yang begitu sempurna diciptakan oleh Tuhan mempunyai banyak kelebihan serta menjadi panutan suri tauladan yang baik (uswah hasanah) bagi umat manusia. Namun, sesungguhnya apakah pelajaran penting di balik pesan yang begitu mendalam bagi manusia, sehingga tidak diutusnya lagi Nabi setelah beliau? Harus dimengerti, sebagai manusia yang hidup paska 14 abad kewafatan Nabi saw, sifatsifat pada diri Nabi, kesemuanya menjadikan manusia perlu untuk memilikinya sebagai sumber inspirasi nomor wahid dalam kehidupan, sebagaimana telah dituliskan oleh M Hart dalam bukunya 100 orang paling berpengaruh di dunia yang meletakkan Nabi Muhammad saw diurutan paling pertama.

Al-Qur'an menyebutkan, bahwa diutusnya sang Nabi sebagai rahmat bagi seluruh alam (rahmat li al-'alamin). Membentuk masyarakan yang madani penuh dengan peradaban. Sebagai masyarakat yang masih murni atau masyarakat yang diatur secara organisasi modern, haruslah dikelola dan diurus serta dikendalikan secara ilmiah oleh orangorang yang berilmu pengetahuan mengenai kemasyarakatan, seperti sosiologi, ilmu pemerintahan, ilmu jiwa masyarakat, antropologi, ilmu politik, ilmu ekonomi, ilmu hukum dan lain-lain yang mana kesemuanya harus didasarkan pada iman dan amal saleh. ${ }^{6}$ Dari berbagai macam bidang ilmu tersebut, Nabi merupakan orang yang dapat membentuk peradaban Arab, membentuk karakter para sahabat seperti, mencetak panglima perang, diplomat, ahli ilmu, pendidik dan lain-lain.

${ }^{6}$ Mochtar Effendi, Bangunan Masyarakat Islam (Palembang; Penerbit Universitas Sriwijaya bekerja sama dengan Yayasan Pendidikan dan Ilmu islam “Al-Mukhtar, 2002), hlm. 298. 
Islam datang menyempurnakan syariat-syariat sebelum datangnya Nabi Muhammad saw. Al-Qur'an sebagai kitab suci umat Islam merupakan wahyu kenabian saw, tidak lagi memerlukan penjelasan pada kitab-kitab suci sebelumnya, seperti Injil yang masih memerlukan penjelasan pada kitab Taurat, kitab Taurat masih memiliki pemahaman yang bersandar pada kitab Zabur. Hal ini menunjukan, Al-Qur'an mempunyai nilai plus dari kitab-kitab suci sebelumnya sebagai kitab suci penyempurna. Karekter kitab suci Al-Qur'an sebagai salah satu mukjizat Nabi Muhammad saw adalah sumber berbagai macam ilmu, baik berkenaan tentang kisah orang-orang terdahulu (qas\}as), berkaitan dengan masa yang akan datang (yaumu al-qiyamat) dan lain-lain. Hal ini, mempunyai kaitan erat dengan hadis-hadis Nabi saw untuk mengetahui beberapa maknanya yang bersifat global dengan melihat asbāb alnuzūl ayat.

Berkenaan dengan tema yang diangkat di sini, berawal dari sebuah buku yang ditulis oleh seorang ulama berasal dari Suriah bernama 'Abd Fattah Abu Ghuddah yang berjudul al-Rasūl alMua'allim wa Asātỉbuhu fî̀ al-Ta'lim. buku tersebut menjelaskan mengenai sisi seorang pendidik dari Nabi saw dan beberapa cara-cara bagaimana Rasul saw mendidik para sahabat beliau.

Dari berbagai penjelasan yang telah diuraikan, akan lebih dikhususkan pembahasan ini pada sosok Nabi sebagai seorang pendidik. Bagaimana metode yang diajarkan Nabi dalam membina para sahabat, Apa rahasia pengajaran Nabi sehingga dapat membentuk karakter para sahabat, sehingga dapat muncul sosok panglima perang, diplomat yang handal, ahli strategi berperang, ahli ilmu yang rendah hati, sosok pemimpin dan sebagainya?

\section{METODE PENELITIAN}

Dimana telah dipaparkan di atas, fokus utama penelitian ini adalah mengkaji gagasan dan interpretasi seorang tokoh tahqiq kitab. Jenis penelitian yang digunakan merupakan studi literatur (Library research) atau penelitian pustaka, ${ }^{7}$ yaitu merupakan serangkaian kegiatan yang berkenaan dengan metode pengumpulan data pustaka, membaca dan mencatat serta mengolah bahan penelitian, ${ }^{8}$ hal ini mengacu pada buku-buku dan datadata karya ilmiah yang berkaitan dengan pembahasan penelitian.

${ }^{7}$ Lihat Muhammad Sabana dan Sudrajat, Dasar-Dasar Penelitian Ilmiah, (Bandung: Pustaka Setia, 2001), hlm. 77

${ }^{8}$ Lihat Mestika Zed, Metode Penelitian Kepustakaan, (Jakarta: Yayasan Obor Indonesia, 2004), hlm. 3. 
Oleh karena itu, sumber data sumber data yang diperoleh dari berbagai kitab yang telah ditelah dan dibaca.Dengan upaya ini diharapkan dapat memberikan informasi yang valid serta akurat. Metode utama yang dipakai dalam kajian ini yaitu metode deskriptif-analitis, yakni penelitian yang berusaha menuturkan masalah yang diselidiki dengan menggambarkan keadaan secara obyektif. ${ }^{9}$

\section{Konsep Pendidikan dalam Islam}

Dalam menetapkan sebuah konsep, Islam selalu memperhatikan nilai-nilai positif yang sesuai dengan ajaran alQur'an dan Sunnah. Suatu nilai-nilai pendidikan yang mempunyai pagar-pagar yang tidak boleh melewati gerbang syariah, di mana telah diatur oleh ajaran risalah Nabi saw. Sedangkan, sebagai suatu sistem, pendididikan secara umum harus memiliki beberapa aspek yang mempunyai keterkaitan antara satu dengan yang lainnya. Diantaranya, tujuan pendidikan, kurikiulum, metode, guru, hukuman dan lingkungan, ${ }^{10}$ di mana hubungan tersebut telah termuat dalam beberapa buku-buku pengembangan

\footnotetext{
9 Hadari Nawawi, Metode Penelitian Bidang Sosial, (Yogyakarta: Gajah Mada University Press, 2003), hlm. 63.

10 Abudin, Konsep Pendidikan Ibn Sina (Jakarta, Disertasi Institut Agama Islam Negeri Syarif Hidayatullah 1997), hlm. 212; Kini telah berubah statusnya menjadi Universitas Islam Negeri Syarif Hidayatullah.
}

pendidikan pada era modern saat ini. Namun tetap saja, konsep yang baik merupakan konsep yang tersusun dengan rapi, dapat dipahami, mempunyai rukunrukun sehingga dapat menghasilkan jiwajiwa pendidik yang penuh karekter dengan tanpa diliputi niatan yang buruk sehingga dapat merusak kepribadian yang dididik. Hal ini, dapat diaplikasikan secara baik dan benar tanpa merusak kepripadian personal.

Kedudukan Islam, sebagai agama dan sumber (marja') pendidikan yang dibawa oleh Muhammad saw sebagai Nabi pembawa risalah Ilahi, mempunyai maksud yang berdasarkan pada dua kesaksian (shahadatain): aku bersaksi bahwa tiada Tuhan melainkan Allah, dan bahwa Muhammad adalah utusan Allah. Jadi Islam adalah agama yang berpedoman pada kitab suci Al-Qur'an dan Hadis Muhammad saw (570-632 M) sebagai utusan terakhir Allah. ${ }^{11}$

Menurut Abdul Majid Khan, dalam bukunya "Pendidikan Karakter Perspektif islam", ada tiga nilai yang menjadi pilar pendidikan karakter dalam islam. Maka dalam pendidikan, islam merujuk akhlak sebagai tugas dan tanggung jawab selain syariah dan ajaran Islam. Sedangkan adab merujuk kepada sikap dihubungkan dengan

11 S.I. Poeradisastra, Sumbangan Islam kepada Ilmu dan Peradaban Modern, (Jakarta; Komunitas Bambu 2008), hlm. 1. 
tingkah laku yang baik. Dan keteladanan merujuk kepada kualitas karakter yang ditampilkan oleh seorang muslim yang baik yang mengikuti keteladanan Nabi Muhammad saw. Jadi pendidikan yang diajarkan oleh Nabi saw merupakan bagian dari pendidikan karekter dengan menitikberatkan pada pondasi awalnya melalui penguatan akidah para sahabat Nabi saw.

Konsep usaha pendidikan karakter identik dengan ajaran agama, yang mempunyai perbedaan dengan konsep yang diterapkan dalam pendidikan di Barat. Letak perbedaan tersebut pada penekanannya terletak pada prinsip-prinsip agama yang abadi, aturan dan hukum dalam memperkuat moralitas, perbedaan pemahaman tentang kebenaran, penolakan terhadap otonomi moral sebagai tujuan pendidikan moral, di mana letak perbedaan-perbedaan ini pada keberadaan wahyu Ilahi sebagai sumber dan karakter dalam Islam. ${ }^{12}$ Dan hal ini, menyebabkan para pakar pendidikan seperti Muhammad Abduh, Sayyed Husen Nasr, Naquib AlAttas dan Wan Daud menawarkan pendekatan melalui pertanyaan, bagaimana pendidikan karekter Barat bisa diterapkan?

${ }^{12}$ Abdul Majid Khan dan Dian Andayani, Pendidikan Karakter Perspektif Islam, (Bandung, PT Remaja Rosda 2013), 58.

\section{Rasulullah Seorang Pendidik}

a. Ungkapan al-Qur'an bahwa Rasulullah seorang pendidik.

1. Al-Qur'an surah al-Jum'ah ayat 2

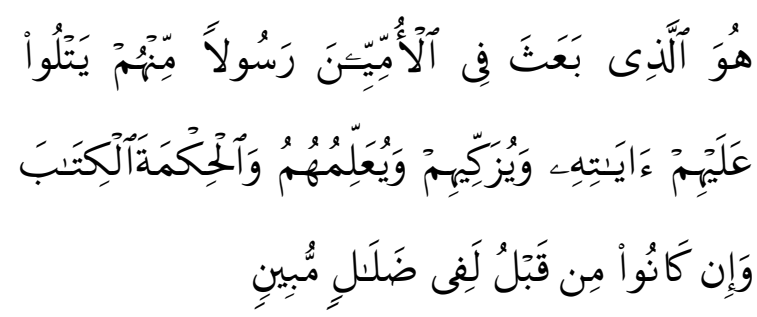

Artinya:

Dia-lah yang mengutus kepada kaum yang buta huruf seorang Rasul di antara mereka, yang membacakan ayat-ayat-Nya kepada mereka, mensucikan mereka dan mengajarkan mereka kitab dan Hikmah (As Sunnah). dan Sesungguhnya mereka sebelumnya benar-benar dalam kesesatan yang nyata.

2. Surah al-Nisa' ayat 79

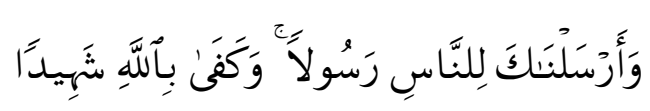

Artinya:

Kami mengutusmu menjadi Rasul kepada segenap manusia. dan cukuplah Allah menjadi saksi.

3. Surah Saba' ayat 27

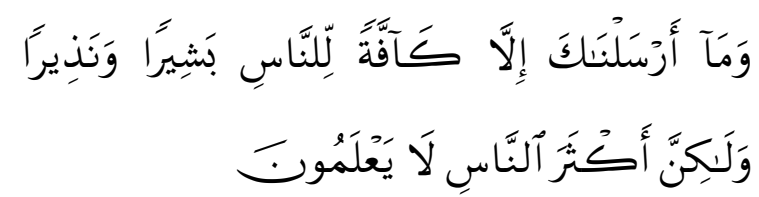

Artinya:

Dan Kami tidak mengutus kamu, melainkan kepada umat manusia seluruhnya sebagai pembawa berita gembira dan sebagai pemberi peringatan, tetapi kebanyakan manusia tiada mengetahui.

Di dalam kandungan al-Qur'an yang begitu luas, tentunya tidak hanya tiga ayat di atas saja yang membicarakan 
mengenai sosok Nabi Muhammad saw sebagai guru, dan tentu masih banyak ayatayat yang menjelaskan kedudukan Nabi saw seorang pribadi pendidik bagi para sahabat beliau serta umat yang hidup setelah wafatnya Nabi.

b. Beberapa Ketetapan dalam Hadis bahwa Rasulullah saw Seorang Pendidik

1. Hadis riwayat Ibnu Majah

$$
\begin{aligned}
& \text { روي ابن ماجه في سننه والدارمي في سننه, واللفظ } \\
& \text { لابن ماجه, حدثنا بشربن هلال الصواف حدثنا داود } \\
& \text { بن الزبرقان عن بكر بن خحنيس عن عبد الرحمن بن }
\end{aligned}
$$

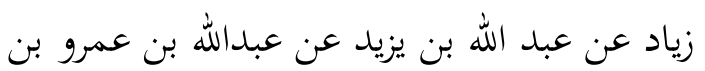

$$
\begin{aligned}
& \text { العاص رضي الله عنهما, قال: خرج رسول الله صلى رئ لهن } \\
& \text { الله عليه وسلم ذات يوم من بعض حجره فدخل } \\
& \text { المسجد, فإذاهو بحلفتين: إحداهما يقرؤون القران } \\
& \text { ويدعون الله تعالى, والأخرى يتعلمون ويعلمون, } \\
& \text { فقال النبي صلى الله عليه وسلم: كل على خير, } \\
& \text { هؤلاء يقرؤون القران ويدعون الله, فإن شاء أعطاهم } \\
& \text { الله وإن شاء منعهم, هاؤلاء يعلمون ويتعلمون, إنما } \\
& \text { بعثت معلما, فجلس معهم } 13
\end{aligned}
$$

Artinya:

Telah menceritakan kepada kami Bisyr bin Hilal Ash Shawwafi berkata, telah menceritakan kepada kami Dawud bin Az Zibirqan dari Bakr bin Khunais dari

${ }^{13}$ Hadis riwayat Imam Ibnu Majah, No. Hadis: 229; 1: 83, bab Faḍlu al-'Ulama wa alhaththu 'ala Talab al-'Ilm (17), di-tahqiq oleh Muhammad Fuad 'Abdul Baqi, (Matba'ah Dar alIhya al-Kutub al-'Arabiyyah); Al-Darimi (Tab'ah Hindiah), hlm. 45.
Abdurrahman bin Ziyad dari Abdullah bin Yazid dari Abdullah bin 'Amru ia berkata; Pada suatu hari Rasulullah shallallahu 'alaihi wasallam keluar dari salah satu kamarnya dan masuk ke dalam masjid. Lalu beliau menjumpai dua halaqah, salah satunya sedang membaca Al Qur'an dan berdo'a kepada Allah, sedang yang lainnya melakukan proses belajar mengajar. Maka Nabi shallallahu 'alaihi wasallam pun bersabda: "Masing-masing berada di atas kebaikan, mereka membaca Al Qur'an dan berdo`a kepada Allah, jika Allah menghendaki maka akan memberinya dan jika tidak menghendakinya maka tidak akan memberinya. Dan mereka sedang belajar, sementara diriku diutus sebagai pengajar, " lalu beliau duduk bersama mereka.

2. Hadis riwayat Imam Muslim

$$
\begin{aligned}
& \text { وروي مسلم في كتاب الطلاق من صحيحه, في } \\
& \text { قصة تخيير النبي صلى الله عليه وسلم زوجاته } \\
& \text { الشريفات رضي الله عنهن, وقد بدأ بعائشة منهن } \\
& \text { فاختارته رضي الله عنها, ورغبت منه أن لا يخبرغيرها } \\
& \text { أها اختارته, فقال لها عليه الصلاة والسلام: إن الله } \\
& \text { لم يبعثني معنتا ولامتعنتا, ولكن بعثني معلما ميسرا14 }
\end{aligned}
$$

Artinya:

Imam Muslim meriwayatkan dalam kitab Talak dari kitab Sahih-nya, pada suatu kisah, Nabi Shallah 'alaihi wa Sallam memberikan pilihan kepada para istri Nabi (radhiya Allah 'anhunna), dan Nabi memulainya dari 'Aisyah, maka ia ('Aisyah radhiya Allahu 'anha) memilih Nabi, serta menginginkan agar Nabi tidak mengatakannya kepada yang lain (para istri Nabi r.a). Maka Rasulullah saw bersabda: Sesungguhnya Allah tidak mengutusku untuk memaksa seseorang

14 Hadis riwayat Imam Muslim, No. Hadis: 1478, Kitab al-Ṭāāq (18: 29), (Riyadh: Bait al-Afkar al-Dauliyyah li al-Nashr wa al-Tauzi' 1997). 
atau menjerumuskannya, akan tetapi Dia mengutusku sebagai seorang pengajar yang memudahkan urusan manusia.

Rasulullah sebagai seorang guru telah disebutkan dari beberapa ayat alQur'an dan hadis yang telah tercantum di atas. Hal ini menunjukan, bahwa selain sebagai seorang Rasul utusan Allah, Nabi Muhammad saw merupakan sosok pendidik yang patut dijadikan figur utama dalam menjalani kehidupan, terutama dari sisi jiwa pendidik yang beliau miliki. Diturunkannya ayat al-Qur'an yang pertama sebagaimana yang telah ditulis sebelumnya, Nabi diminta oleh Malaikat Jibril untuk membacakan kata “ قرأ ، hingga tiga kali. Bahwasanya hal ini mempunyai makna di mana kunci dari suatu perubahan adalah dengan membaca, kemudian diiringi dengan perbaikan akhlak, sebagaimana apa yang telah dilakukan oleh Nabi Muhammad saw pada saat periode Makkah.

\section{Karakter Pendidikan Rasulullah}

Pendidikan yang diajarkan oleh Nabi saw kepada para sahabat radiya Allahu 'anhum menjadikan derajat mereka terangkat. Muncul dari negeri Arab yang gersang jauh dari peradaban, yang mempunyai kebiasaan jahiliyah dan Barbariah kemudian berubah menjadi kebiasaan yang sangat mengerti akan arti jiwa bersosial, mempunyai akhlak dan kepribadian jujur, terbukti dari beberapa sahabat tercetak orang-orang yang berjiwa pemimpin, negarawan, diplomat, panglima perang, ilmuwan yang beriman, hartawan yang dermawan serta kepribadiankepribadian baik lainnya.

Menurut 'Ali Muhammad Salabi dalam bukunya al-Sirah al-Nabawiyah ${ }^{15}$ Ada lima pendidikan awal Rasulullah berkenaan dengan pembentukan karekter para sahabat, terutama konstruksi dan akhlak pada fase Makkah. Diantaranya adalah:

a. Penyucian jiwa kaum muslimin generasi pertama dengan beragam ibadah. Ibadah shalat merupakan sebagai awal pengaruh besar dalam penyucian jiwa kaum muslimin. Dalam hal ini pendidikan terpenting yang diajarkan Nabi adalah pertama, perenungan (tadabbur) alam semesta beserta makhluk-makhluk dan KitabNya; kedua, mempelajari ilmu Tuhan secara komprehensif baik bersifat nyata maupun ghaib; ketiga, beribadah kepada Tuhan merupakan sarana paling utama dalam mendidik rohani.

b. Pendidikan akal, sebagaimana yang diajarkan oleh Nabi saw adalah pendidikan secara komprehensif, menyeluruh. Karena ia bersandar

15 'Ali Muhammad Salabi, al-Sirah alNabawiyyah; 'Ardu Waqā'i wa Tahlilu Ahdath, (Kairo, Muassasah Iqra', 2005), hlm. 108-112. 
kepada al-Qur'an menjelaskan kepada manusia secara keseluruhan. Oleh karena itu, al-Qur'an menetapkan sebuah konsep bagi pendidkan akal. Di antara poin penting dari pendidikan ini adalah, pertama, mengosongkan akal dari nilai-nilai yang bersandar pada prasangka, khayalan, taqlid dan fanatik; kedua, menetapkan akal untuk kritis tapi berprinsip; ketiga, menyeru akal untuk berpikir dan mengkaji alam semesta; keempat, mengajak akal untuk merenungkan rahasia di balik sharia Allah; kelima, menyeru akal untuk merenungkan sunatullah yang terjadi pada manusia dari perspektif sejarah manusia.

c. Pendidikan fisik. Pendidkan yang cenderung ekonomistis, rasional dan artifisial akan dapat merendahkan derajat manusia serta mengakibatkan terabaikannya personalitas dan spiritualitas manusia, sehingga manusia mulai kehilangan keutuhan hidupnya sebagai human. Hal ini antara lain menjadi penyebab timbulnya berbagai kekerasan dan keterasingan sosial, politik, ekonomi, bahkan budaya yang bertentangan dengan tujuan ideal pendidikan itu sendiri. ${ }^{16}$ Pendidikan

\footnotetext{
Najmuddin Ramly, Membangun Pendidikan yang Memberdayakan dan Mencerahkan; Teologi Humanisme, Fondasi
}

tersebut sangat bertentangan dengan prinsip yang diajarkan oleh Nabi saw. Pendidikan yang bersifat fisik tetap bersandar kepada al-Qur'an sebagaimana tujuannya untuk menjadikan tubuh dapat melaksanakan tugasnya sesuai dengan tujuan diciptakannya tanpa berlebihan. Oleh karenanya al-Qur'an mengatur berbagai kebutuhan tubuh manusia: 1) Mengatur kebutuhan manusia terhadap makan dan minum; 2) Mengatur kebutuhan terhadap pakaian dan tempat tinggal, dengan cara menutup aurat; 3) Mengatur kebutuhan manusia terhadap tempat tinggal; 4) Mengatur kebutuhannya terhadap pernikahan hidup berkeluarga; 5) Mengatur kebutuhan manusia untuk memiliki kekayaan dan kekuasaan sesuai dengan aturan syariat; 6) Islam mengatur kekuasaan dengan cara mengharamkan prilaku dzalim dan permusuhan; 7) Mengatur kebutuhan manusia terhadap bekerja dan kesuksesan dengan menetapkan pekerjaan yang disyariatkan; dan 8) Allah mengingatkan manusia agar tidak sombong dan angkuh dan berbangga diri.

pendidikan di Tengah Perubahan, (Jakarta, Penerbit Grafindo Khazanah Ilmu 2005), hlm. 194. 
Inilah beberapa pokok dasar pengaplikasian Nabi dalam pendidikan fisik yang diajarkan kepada para sabahat r.a, dengan tujuan agar mereka mampu mengemban beban berat jihad dalam menghadapi tantangan da'wah dan kesulitan hidup.

d. Pendidikan akhlak untuk para sahabat dan mensucikan mereka dari akhlak buruk. Berkenaan dengan pendidikan akhlak, Muhammad Ali al-Salabi mengutip hadis dari Imam tirmidzi, Rasulullah saw bersabda,

$$
\text { ما من شنئ أثقل في ميزان المؤمن يوم القيامة من }
$$

Artinya:

Dari Rasulullah saw bersabda, tidak ada yang lebih berat pada timbangan (pahala) seorang mukmin di akhirat (kelak) melebihi dari akhlak yang baik, dan sesungguhnya Allah sangat membenci orang yang jahat dan buruk akhlaknya.

Menurut Muhammad Ali alSalabi, Hadis riwayat Imam Tirmidzi di atas ingin mengatakan bahwa, akhlak mulia justru merupakan bagian penting dari akidah. Itu dikarenakan akidah

${ }^{17}$ Imam Tirmidzi, Al-Jāmi' al-Kabir li al-

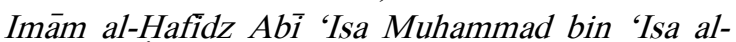
Tirmídzi, di-tahqiq oleh Duktur Bahar 'Awad Ma'ruf, kitab al-Bir wa al-Silāh, bab Mā Jā a fi Husni al-Khulq, No. Hadis: 2002, hadis hasan sahih, (Dar al-Gharb al-Islamy, 1996). yang benar akan menghasilkan akhlak yang baik pula.

\section{Pendidikan akhlak Nabi} saw merupakan sesuatu yang komprehensif, meliputi semua tingkah laku manusia, setiap perasaan dan pemikirannya. Dalam shalat terdapat akhlak, yaitu khusyu'. Ketika berbicara terdapat akhlak, yaitu berpaling dari senda gurau yang tak bermanfaat. Dalam hubungan suami istri terdapat akhlak, yaitu konsisten dengan batasanbatasan yang dilarang oleh Allah dan yang diharamkan oleh-Nya. Dalam berinteraksi terdapat akhlak, yaitu antara berlebihan dan anti bergaul. Kehidupan dalam berjama'ah ada akhlak, yaitu bermusyawarah dengan manusia. Ketika marah terdapat akhlak, yaitu memaafkan dan tidak dendam. Serta adanya permusuhan terdapat akhlak, dengan cara memenangkan dan menolak permusuhan. ${ }^{18}$ Dengan demikian tidak ditemukan satupun dalam kehidupan seorang muslim tanpa adanya akhlak.

e. Pendidikan akhlak para sahabat melalui kisah-kisah al-Qur'an. Kisah-kisah yang terdapat dalam al-Qur'an mencakup ruang lingkup tauhid, akhlak mulia, ilmu, argument-argumen pemikiran,

${ }^{18}$ Muhammad Ali al-Salabi, al-Sirah alNabawijyyah: 'Arḍu waqā i' wa Taḥlil Ahdath (Kairo, Muassah Iqra', 2005), hlm. 111-112. 
penjelasan, peringatan dan lain-lain.

Berikut beberapa kisah dari Nabi Yusuf a.s yang disebutkan dalam al-Qur'an.

1. Terjaga dari nafsu dan syahwat.

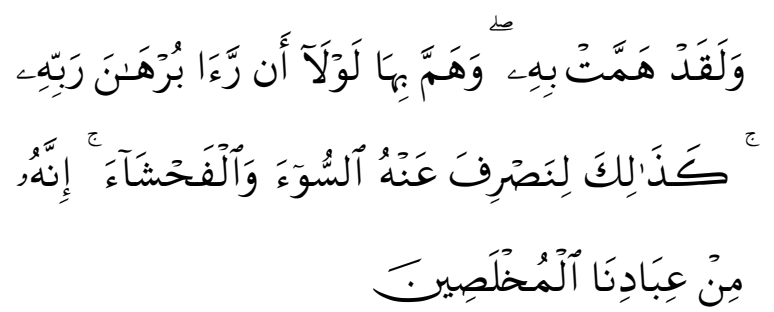

Artinya:

Sesungguhnya wanita itu telah bermaksud (melakukan perbuatan itu) dengan Yusuf, dan Yusuf pun bermaksud (melakukan pula) dengan wanita itu andaikata Dia tidak melihat tanda (dari) Tuhannya. Demikianlah, agar Kami memalingkan dari padanya kemungkaran dan kekejian. Sesungguhnya Yusuf itu Termasuk hambahamba Kami yang terpilih. (Q.S Yusuf: 24).

2. Bersabar ketika marah.

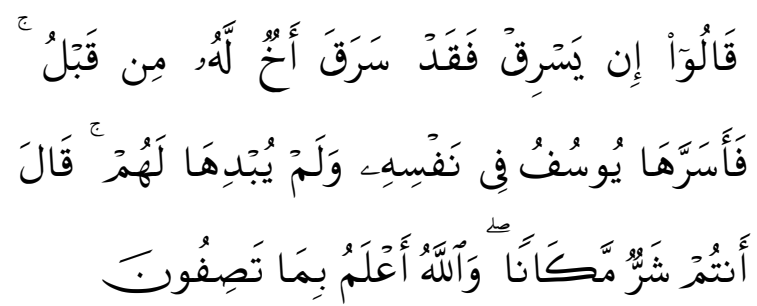

Artinya:

Mereka berkata: "Jika ia mencuri, Maka Sesungguhnya, telah pernah mencuri pula saudaranya sebelum itu". Maka Yusuf Menyembunyikan kejengkelan itu pada dirinya dan tidak menampakkannya kepada mereka. Dia berkata (dalam hatinya): "Kamu lebih buruk kedudukanmu (sifat-sifatmu) dan Allah Maha mengetahui apa yang kamu terangkan itu". (Q.S Yusuf: 77).
3. Memiliki perspektif tajam dan naluri yang kuat.

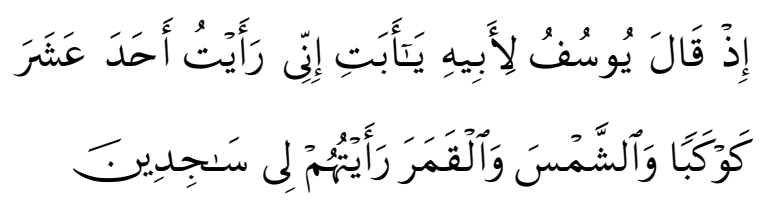

Artinya:

(ingatlah), ketika Yusuf berkata kepada ayahnya: "Wahai ayahku. Sesungguhnya aku bermimpi melihat sebelas bintang, matahari dan bulan; kulihat semuanya sujud kepadaku."

(Q.S Yusuf: 4).

4. Mempersiapkan diri dengan ilmu, mencintai dan mempersiapkannya.

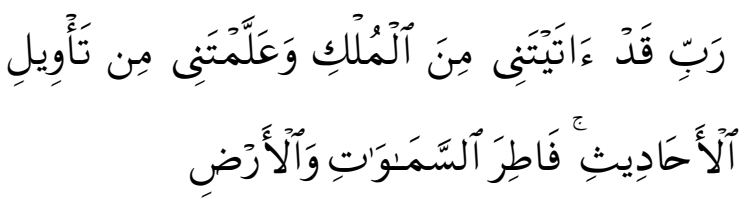

Artinya:

Ya Tuhanku, Sesungguhnya Engkau telah menganugerahkan kepadaku sebahagian kerajaan dan telah mengajarkan kepadaku sebahagian ta'bir mimpi. (ya Tuhan) Pencipta langit dan bumi.

(Q.S Yusuf: 101).

Demikianlah, beberapa nilai pendidikan yang diberikan oleh Nabi saw kepada para sahabat melalui konstruksi ibadah dan akhlak terutama yang terjadi pada fase Makkah.

\section{Gaya Dakwah dalam Pengajaran Nabi SAW}

Pendidikan dan pengajaran yang dipilih oleh Nabi Muhammad saw dalam mendidik para sahabat, dipilihnya dengan cara-cara yang terbaik, sehingga mudah 
dipahami dan diaplikasikan dengan tidak perlu lagi muncul banyak pertanyaan dari orang yang dididik. Tentunya bentuk pendidikan yang disampaikan sesuai sebagaimana nilai-nilai dari wahyu yang telah Allah turunkan melalui perantara malaikat Jibril kepada Nabi saw.

Di antara gaya pengajaran Nabi saw kepada para sahabat yaitu:

a. Pengajaran Nabi saw melalui perjalanan hidup yang baik dan mencontohkan akhlak mulia

Gaya pengajaran ini ditunjukan Nabi saw agar para sahabat dapat mencontoh segala macam tingkah laku perbuatan Muhammad sebagai utusan Allah, yang mempunyai uswah hasanah. Allah telah menyatakan dalam a-Qur'an
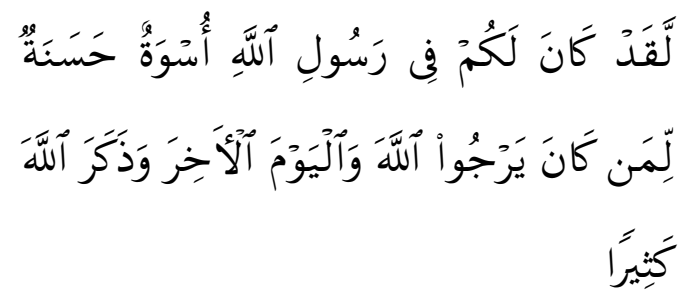

Artinya:

Sesungguhnya telah ada pada (diri) Rasulullah itu suri teladan yang baik bagimu (yaitu) bagi orang yang mengharap (rahmat) Allah dan (kedatangan) hari kiamat dan Dia banyak menyebut Allah. (QS alAhzab: 21).

\section{Menurut 'Abd Fattah Abu} Ghuddah dalam bukunya al-Rasūl alMu'allim, bahwa tidak diragukan lagi pendidikan melalui perbuatan dan tingkah laku lebih kuat melekatnya pada diri seseorang, serta mudah dipahami dan dijaga. ${ }^{19}$

Pada kitab al-Is\}abah fi Tamyiz al-S\{ahabah karya Imam alHafidz Ibnu Hajar di dalam biografi sahabat (al-Julanda Raja Oman): "Wathimah telah menyebutkan dalam kitab al-Riddah dari Ibnu Ishaq bahwa Nabi shallahu 'alaihi wa sallam mengirim 'Amru bin 'Ash kepadanya (Julanda), untuk mengajaknya kepada Islam. Maka ia berkata: "Telah menunjukan kepadaku seorang Nabi yang buta huruf (ummiy), Beliau tidak memerintahkan kepada kebaikan melainkan beliau yang pertama mengerjakannya, tidak melarang kepada keburukan melainkan orang pertama yang meninggalkannya, beliau mengutamakan tidak menolak, diutamakan tidak meninggalkan, tidak mengatakan perkataan buruk, menjaga perjanjian, menepati janji maka aku bersaksi bahwa beliau adalah Nabi saw.

$$
\begin{array}{rlccc}
\text { Imam } & \text { Syatibi } & \left(\begin{array}{lll}
\text { w } & 790 & \mathrm{H}
\end{array}\right) \\
\text { mengatakan } & \text { dalam kitabnya } & \text { al- }
\end{array}
$$
I’t $\}$ is $\{a m$, bahwa Rasulullah shallahu 'alaihi wa sallam akhlaknya al-Qur'an,

\footnotetext{
19 'Abd Fattah Abu Ghuddah, al-Rasūl alMu'allim wa AsāTíbuhu fỉ al-Ta'Tim (Beirut, Dār al-Bashāir al-Islamìyah 2008), hlm. 65.
} 
karena pada dirinya terdapat wahyu Ilahi, sehingga yang dilakukan sejalan dengan ilmu yang dimiliki. Maka dari itu, dapat dikatakan bahwa wahyu kecocokan perkataan penurutan yang responsive terhadap hukumnya. Khusus untuk dalil-dalil yang kuat atas kebenaran dengan datangnya beliau. Apabila terdapat nasehat beliau yang akan menjalankan nasehat tersebut, jika hal yang ditakuti beliau yang pertama menjadi orang yang takut (takut dengan dosa), jika ada harapan beliau yang menjadi pengendali harapan itu dan hakikat seluruhnya. Oleh karena itu, Nabi Muhammad menjadi seorang hamba Allah ('Abdullah) yang haqq, merupakan nama yang paling mulia dari namanama hamba-hamba Allah. Difirmankan dalam al-Qur'an

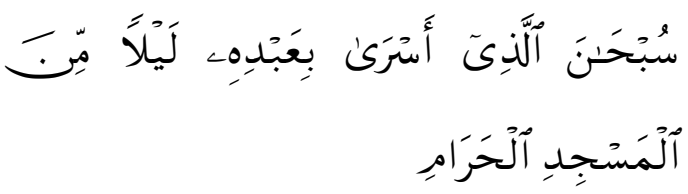

Artinya:

Maha suci Allah, yang telah memperjalankan hamba-Nya pada suatu malam dari Al Masjidil Haram.... (QS. al-Isra: 1).

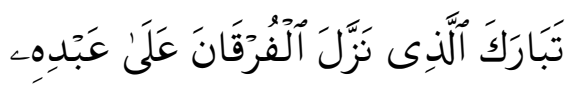

Artinya:

Maha suci Allah yang telah menurunkan Al Furqaan (Al Quran) kepada hamba-Nya (QS. Al-Furqan: $1)$.

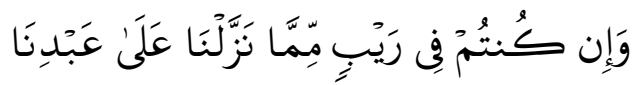

Artinya:

dan jika kamu (tetap) dalam keraguan tentang Al Quran yang Kami wahyukan kepada hamba Kami (Muhammad) (QS. AlBaqarah: 23).

b. Nabi saw Mengajarkan syariat dengan cara bertahap

Proses dalam membentuk karakter seseorang sangat diperlukan dalam pendidikan, tidak mesti lalu menghasilkan dengan cara yang instant. Dalam teknik pengajarannya, Rasul saw mengajarkan satu persatu syariat hingga para sahabat paham secara mendalam secara definisi dan aplikasi nilai dari satu syariat tersebut, kemudian diaplikasikannya dalam kehidupan mereka serta meresap sampai ke hati dengan terhindar dari rasa keraguan dalam menjalakannya.

Berkenaan pengajaran Rasul yang mempunyai gaya bertahap dalam mendidik, di sini ada sebuah hadis dari Imam Ibnu Majah, menjelaskan tentang proses pendidikan yang diawali dengan iman lalu pembelajaran alQur'an.

$$
\text { الله عنه قال: كنا مع النبي صلى الله عند عند عبدالله رضي }
$$




$$
\begin{aligned}
& \text { وسلم, ونحن فتيان حزاورة, فتعلمنا الإيمان قبل } \\
& \text { أن نتعلم القران, ثم تعلمنا القران فازددنا به } \\
& \text { الإيمان }
\end{aligned}
$$

Artinya:

Diriwayatkan oleh Ibnu Majah dari Jundab bin Abdillah radhiya Allahu 'anhu ia berkata: kami bersama Nabi shallahu 'alaihi wa sallam, dan kami masih muda (mendekati baligh). Maka kami belajar mengenai iman sebelum mempelajari al-Qur'an, kemudian setelah itu kami mempelajari alQur'an maka bertambah iman kami.

Pada hadis yang lain, diriwayatkan oleh Imam Bukhari dan Imam Muslim, berkenaan dengan bagaimana proses berdakwah dengan metode satu demi satu syariat diajarkan kepada suatu kaum.

$$
\begin{aligned}
& \text { روي البخاري و مسلم, واللفظ له, عن ابن عباس } \\
& \text { رضي الله تعالي عنهما: أن النبي صلي الله عليه } \\
& \text { وسلم بعث معاذ إلي اليمن, فقال: إنك ستأتي قوما } \\
& \text { من أهل الكتاب, فادعهم إلي شهادة أن لا أله ألا } \\
& \text { الله وأني رسول الله, فإن هم أطاعوا لذلك فأعلمهم } \\
& \text { أن الله قد افترض عليهم صدقة, تؤخذ من أغنيائهم } \\
& \text { فترد علي فقرائهم, فإن هم أطاعوا لذلك فإياك } \\
& \text { وكرائم أموالهم, فإنه ليس بينهما وبين الله حجاب } 21
\end{aligned}
$$

${ }^{20}$ Imam Ibnu Majah, Sunan al-Hafìdz Abi 'Abdillah Muhammad bin Yazìd al-Qazwiny Ibnu Majah, di-tahqiq oleh Muhammad Fuad 'Abdul Baqi, dalam Muqaddimahnya, 61, bab Iman 1:10, sanadnya sahih. (Matba'ah Dar al-Ihya al-Kutub al-'Arabiyyah).

${ }^{21}$ Imam Bukhari di dalam kitab Sahih-nya 1: 160, kitab Ilmu, bab: Ilmu sebelum perkataan dan perbuatan. (Imam Bukhari: kitab al-Zakat, 1496, (1 dan 63): 160, kitab Maghazi (60); Imam
Artinya:

Diriwayatkan oleh Imam Bukhari dan Imam Muslim, dan lafaznya dari Imam Muslim, dari Ibnu 'Abbas radhiya Allahu Ta'ala 'anhuma: Bahwasanya Nabi shallahu 'alihi wa sallam mengirim Mu'adz ke Yaman, maka ia bersabda: Sesungguhnya akan datang kepadamu suatu kaum dari Ahli kitab, maka serulah kepada mereka untuk menyatakan kesaksian, bahwa Tiada Tuhan selain Allah dan aku adalah utusan-Nya. Dan apabila mereka telah mentaatinya maka ajarilah mereka, bahwa Allah mewajibkan kepada mereka untuk bersedekah. Diambilnya kekayaan dari para orang kaya kemudian dibagikan kepada fakir miskin. Dan apabila mereka telah mentaati itu, bagimu kemuliaan dari harta-harta mereka, serta berhatihatilah terhadap do'a orang yang terzalimi, bahwasanya tidak ada hijab antaranya dan Allah.

Demikian dua hadis yang dapat dikutip mengenai pembahasan ini, dan masih banyak lagi hadis yang menjelasakan bahwa Rasulullah mengajarkan sebuah proses dalam berdakwah, mengajar suatu syariat kepada para umatnya, agar mereka tidak berasa diberatkan dengan apa yang diajarkan oleh Nabi.
Muslim: 29, kitab al-Iman (7); Imam Abu Daud: 1584, bab zakat (4); Imam Tirmidzi: 625, bab Zakat (6); Imam al-Nasa'i: 2435 dan 2522, kitab Zakat (1 dan 46); Imam Ibnu Majah: 1783, kitab Zakat (1); Imam al-Darimi: bab Zakat (1); Imam Ahmad in Hanbal: (1 dan 233). 
c. Gaya mengajar Rasul saw dengan berdialog dan mengajukan pertanyaan

Salah satu gaya dan cara mendidik Rasulullah saw ialah dengan berdialog dan mengajukan pertanyaan. Karena hal ini lebih membekas pada diri para sahabat Nabi yang mendengarkannya, kemudian disertai dengan jawaban sesuai dengan takaran pemahaman teman berdialog beliau saw. Hal ini, dilakukan oleh Nabi agar dapat membuka pemahaman kepada mereka dari kunci gembok yang menutupi lintasan pikiran. Hadis dari Imam Bukhari dan Imam Muslim di bawah ini akan menunjukan bahwa cara seperti ini pernah dilakukan oleh Nabi Muhammad saw kepada sahabat.

$$
\begin{aligned}
& \text { روي البخاري ومسلم, واللفظ له, عن أبي }
\end{aligned}
$$

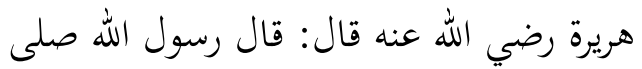

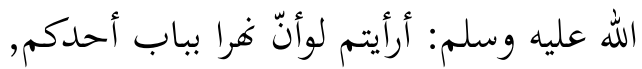

$$
\begin{aligned}
& \text { يغتسل منه كل يوم خمس مرات, هل يبقي من } \\
& \text { درنه شيء؟ قالوا: لايبقي من درنه شيء, قال: } \\
& \text { فذلك مثل الصلوات الخمس يمحوا الله بهنّ } \\
& \text { الخطايا22 }
\end{aligned}
$$

Artinya:

Diriwayatkan dari Imam Bukhari dan Imam Muslim, dan lafaz dari Imam

${ }^{22}$ Imam Bukhari: 528, kitab Mawāqit alSalāh (6); Imam Muslim: kitab Masājid (283, 284), 5: 17; Imam Tirmidzi: Adab (80); Imam alNasa'i: al-Shalah (7); Imam Ibnu Majah: (193) Iqamah; Imam al-Darimi: (1) al-Shalah; Imam Tabharani: (61) safar; Imam Ahmad Ibnu Hanbal: (1)
Muslim, dari Abu Hurairah radhiya Allahu 'anhu, ia berkata: Rasulullah shallahu 'alaihi wa sallam bersabda: Bagaimana menurut kalian, apabila ada sungai di depan pintu rumah salah seorang dari kalian, lalu dia mandi lima kali setiap hari, apakah kalian masih menganggap ada kotoran (daki) yang tersisa padanya? Sahabat menjawab, tidak ada tersisa sedikitpun kotoran padanya. Lalu beliau bersabda: seperti itu pula shalat lima waktu, dengannya Allah akan menghapus semua kesalahan.

Di hadis lain diriwayatkan oleh Imam Ahmad dalam Musnadnya, dari sahabat Abdullah bin 'Amru bin 'Ash

$$
\begin{aligned}
& \text { وروي الإمام أحمد في مسنده, عن عبد الله بن } \\
& \text { عمرو بن العاص رضي الله عنهما, قال: سمعت } \\
& \text { رسول الله صلي الله عليه وسلم يقول: تدرون } \\
& \text { من المسلم؟ قالوا: الله ورسوله أعلم, قال: } \\
& \text { المسلم من سلم المسلمون من لسانه ويده. } \\
& \text { قال: تدرون من المؤمن؟ الله ورسوله أعلم, } \\
& \text { قال: من أمنه المؤمنون علي أنفسهم وأموالهم. } \\
& \text { والمهاجر من هجر السوء فاجتنبه } 23
\end{aligned}
$$

Artinya:

diriwayatkan dari Imam Ahmad bin Hanbal dalam Musnad-nya, dari Abdullah bin Amru bin 'Ash radhiya Allahu 'anhuma, ia berkata: aku mendengar Rasulullah saw bersabda: Apakah kalian tau siapa itu 'Muslim'? mereka menjawab: Allah dan RasulNya yang lebih tau. Ia bersabda: Seorang Muslim adalah ia yang membantu saudara muslim lainnya baik dengan lidahnya maupun tangannya. Lalu beliau kembali

23 Ahmad bin Hanbal, Musnad Imām Ahmad bin Hanbal, (Beirut: Muassasah al-Risalah, 1995); Riwayat Imam Ahmad bin Hanbal Sanadnya sahih, 2: 206. 
bertanya: Apakah kalian tau siapa itu orang beriman? Mereka menjawab: Allah dan Rasul-Nya yang lebih mengetahuinya. Maka beliau bersabda; Orang beriman adalah mereka yang memberikan keamanan kepada orang beriman lainnya terhadap jiwa dan harta mereka. Sedangkan orang yang hijrah adalah, mereka yang menghindari dari segala keburukan.

Di antara hadis yang sering dibahas dan disebutkan berkenaan dengan penngajaran yang dilakukan oleh Nabi melalui tanya jawab yaitu hadis yang dialognya antara Nabi dan malaikat Jibril. Pada saat itu ia sedang dalam bentuk manusia, bertanya tentang Islam, Iman dan Ihsan. Demikian beberapa hadis bentuk pendidikan Rasulullah saw kepada para sahabat berupa dialog serta tanya jawab yang dapat dituliskan. ini merupakan beberapa yang dapat dipaparkan, tentu masih banyak lagi hadis yang belum sempat dituliskan di sini.

d. Pengajaran Rasulullah saw dengan berdialog dan pertimbangan akal.

Bentuk pengajaran Rasulullah selain melalui metode berdialog dan bertanya jawab, beliau juga menerapkan metode dengan cara percakapan dan pertimbangan dangan akal para sahabat pada saat itu. Metode ini hampir mirip dengan metode sebelumnya, namun yang menjadi perbedaan adalah, pada pengajaran ini Rasul saw lebih mengajak akal manusia agar dapat berpikir serta mempertimbangkan mengenai apa yang beliau ajarkan adalah suatu hukum, syariat atau sebuah hikmah. Di antara hadis yang menjelaskan tentang metode ini yaitu, hadis mengenai perempuan, di mana diceritakan oleh hadis ini, makhluk yang paling banyak berada di neraka adalah wanita.

Diriwayatkan oleh Imam

Bukhari dan Imam Muslim, dan lafadznya dari Imam Bukhari dari Abi Sa'id al-Khudri.

$$
\begin{aligned}
& \text { مارواه البخاري ومسلم, واللفظ للبخاري, عن أبي } \\
& \text { سعيد الخدري رضي الله عنه قال: خرج رسول الله } \\
& \text { صلي الله عليه وسلم في أضحي أو فطر إلي المصلي, } \\
& \text { فقال يا معشر النساء تصدقن, فإين أريتكن أكثر } \\
& \text { أهل النار , فقلن: وبم يارسول الله؟ قال: تكثرن }
\end{aligned}
$$$$
\text { اللعن, وتكفرن العشير, ما رأيت من ناقصات عقل }
$$$$
\text { ودين أذهب للب الرجل الحازم من إحداكن. }
$$$$
\text { قلن: ما نقصان ديننا وعقلنا يارسول الله؟ قال: }
$$$$
\text { أليس شهادة المرأة مثل شهادة الرجل؟ قلن: بلي, }
$$$$
\text { فقال: فذلك من نقصان عقلها, أليس إذا حاضت }
$$$$
\text { لم تصل ولم تصم؟ قلن: بلي, قال: فذلك من }
$$

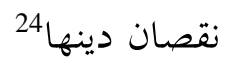

${ }^{24}$ Imam Bukhari Al-Jami' al-Sahīh: alMusnad min Hadith al-Rasulillah Shallallāhu 'alaihi wa Sallam wa Sunanihi wa Ayyāmihi li Abì Abdillah Muhammad bin Ismail al-Bukhāri, 1: 345, 
Artinya:

Hadis diriwayatkan oleh Imam Bukhari dan Imam Muslim, lafadznya dari Imam Bukhari, dari Abi Sa'id alKhudri radhiya Allahu 'anhu, ia berkata: Ketika Rasulullalh sedang keluar untuk melaksanakan shalat Ied Adha atau Ied Fitri di tempat shalat, lalu beliau bersabda: Wahai kaum perempuan, percayalah bahwa aku melihat kalian paling banyak berada di neraka. Maka mereka menjawab (dengan pertanyaan): bagaimana bisa ya Rasulullah saw? Rasulullah menjawab: kalian banyak berbuat sesuatu yang dilaknat dan kufur terhadap nikmat, aku tidak melihat dari kekurangan akal dan agama pergi ke pembakaran api bagi lakilaki dari pada perempuan.

Mereka bertanya kepada Nabi saw: Apa yang menjadikan kekurangan akal dan agama kami ya Rasulullah? Rasulullah bersabda: Bukankah syahadat perempuan itu seperti setengah syahadat dari laki-laki? Lalu mereka menjawab: iya, maka Rasul saw meneruskan sabdanya: oleh karena itu, dari kekurangan akalnya (perempuan), bukankan apabila mereka haidh mereka tidak puasa dan tidak shalat? Lalu mereka berkata: benar, dilanjutkan oleh Rasulullah dengan sabdanya: maka dari itulah kekurangan agama bagi perempuan.

Pada buku al-Rasūl al-Mu'allim karya shaikh 'Abd Fattah Abu Ghuddah, dituliskan dua hadis tentang

kitab Haidh, Bab Seorang yang Haidh meninggalkan puasa, (Kairo: Mathba'ah Salafiyyah wa Maktabatuna $1400 \mathrm{H})$; Imam Muslim, Sahih Muslim, 2: 67, Kitab Iman, Bab penjelasan berkurangnya Iman dengan berkurangnya ketaatan, (Riyadh: Bait al-Afkar al-Dauliyyah li al-Nashr wa al-Tauzi' 1997). pembahasan ini. $^{25}$ Pada hakikatnya, metode ini sama dengan metode yang ketiga, namun dalam hal ini peran akal begitu berpengaruh dalam mempertimbangkan kebenaran hukum yang disampaikan oleh Nabi saw dalam bentuk pengajaran yang kepada para sahabat radhiya Allahu 'anhum.

e. Pengajaran Rsulullah saw dengan cara memberi qiyasan dan perumpamaan

Pengaruh pengajaran Rasulullah saw meliputi segala aspek pendidikan pada masa itu. Nabi saw selalu mengajarkan sesuai dengan kebutuhan para sahabat baik berkenaan dengan hukum di mana Nabi saw mengutarakannya dengan dalil-dalil syar'i. Namun, terkadang beliau menyampaikan pengajarannya dengan cara mengutarakan dengan bentuk qiyas $^{26}$, apabila permasalahan hukumnya menyerupai jalan hukum agama walau Nampak berbeda dilihat dari kondisi dan tempat kejadian permasalahan tersebut. Maka beliau menjelaskan dengan perkara yang sama sesuai dengan pengetahuan dalam syariah, fikih dan maqāṣidị̣ā. Dalam

${ }^{25}$ Untuk lebih lengkapnya, lihat 'Abd Fattah Abu Ghuddah, al-Rasūl al-Mu'allim, (Beirut: Maktabah al-Matbu'ah al-Islamiyyah 2008), hlm. 100-102. 
hal ini, Imam Bukhari meriwayatkan hadis terkait pembahsan pengajaran melalui qiyas.

$$
\begin{aligned}
& \text { روي البخاري عن ابن عباس: أن امرأة من } \\
& \text { جهينة, جاءت إلي النبي صلي الله عليه وسلم, } \\
& \text { فقالت: إن أمي نذرت أن تحج, فلم تحج حتي } \\
& \text { ماتت, أفأحج عنها؟ قال: نعم, حجي عنها, } \\
& \text { أرأيت لو كان علي أمك دين أكنت فاقضيته؟ } \\
& \text { قالت: نعم, قال: اقضوا الله الذي له, فإن الله } \\
& \text { أحق بالوفاء }
\end{aligned}
$$

Artinya:

Diriwayatkan oleh Imam Bukhari, dari Ibnu Abbas r.a, bahwasanya seorang perempuan dari Juhainah datang kepada rasulullah shallahu 'alaihi wa sallam, dan ia bertanya: aku mempunyai ibu yang bernazar untuk pergi haji, dan sebelum berangkat haji ibu saya telah meninggal, maka apakah bagi saya untuk melaksanakan haji untuknya? Rasulullah saw menjawab: iya, tunaikanlah haji untuknya, apakah kamu telah melihat jika ibumu mempunyai hutang, apakah engkau akan membayarkannya? Ia menjawab: iya, maka Rasulullah bersabda: lunasilah hutang kepada Allah, sesungguhnya janji Allah yang lebih berhak untuk ditepati. ${ }^{27}$

Hadis di atas menjelaskan bahwa qiyasan mengenai permasalahan ibadah haji yang belum sempat dilakukan sedangkan seseorang yang

${ }^{27}$ Imam Bukhari, al-Jāmi ‘ al-Sahịh, bab al-hajj wa al-nudzūr 'an al-mayyit wa al-Rajul yahujju 'an al-mar'ah, no. Hadis: 1852, (Kairo: alMathba'ah al-Salafiyyah, 1403 H). 18. melaksanakan ibadah tersebut bernazar namun terlebih dahulu meninggal. Perkara ini diqiyaskan kepada wajibnya melunasi hutang kepada manusia, apalagi hutang yang bersangkutan merupakan hutang antara manusia dengan Tuhannya, maka hal itu lebih berhak untuk dilunasi, walau diwakili oleh ahli warisnya atau kerabatnya.

f. Kolaborasi Pengajaran Rasulullah saw antara penyampaian lisan disertai bahasa isyarat

Terkadang sang Nabi saw melakukan metode pengajaran dengan cara berdialog atau melontarkan pertanyaan. Namun adakalanya metode yang disampaikan dengan mengkolaborasikan antara penyampaian lisan dengan isyarat, penjelasan dengan memberikan sebuah gambaran atau menggunakan kedua tangan, sehingga dapat menunjukan bahwa hal tersebut dapat menunjukkan bahwa pentingnya pembahasan yang disampaikan serta mudah bagi para sahabat yang mendengar untuk mengingat pesannya.

Sedangkan hadis yang membahas tentang metode ini, mengutip periwayatan dari Imam Bukhari dan Imam Muslim. 


$$
\begin{aligned}
& \text { روي البخاري ومسام, واللفظ للبخاري, عن } \\
& \text { أبو موسي الأشعري رضي الله عنه قال: رسول } \\
& \text { الله صلي الله عليه وسلم: المؤمنون كالبنيان } \\
& \text { يشد بكضه بكضا, ثم شبّك رسول الله بين } \\
& \text { أصابعيه }
\end{aligned}
$$

Artinya:

Diriwayatkan oleh Imam Bukhari dan Imam Muslim, sedangkan lafadznya berasal dari Imam Bukhari, dari Abu Musa al-Asy'ari radhiya Allahu 'anhu, ia berkata: Rasulullah shallahu 'alaihi wa sallam bersabda: Orangorang beriman ibarat seperti sebuah bangunan, saling menguatkan antara satu dengan lainnya, kemudian Rasul saw menggabungkan kedua jarinya seperti mengikatkan keduanya.

\section{Kemudian hadis dari Imam Muslim dan Imam Tirmidzi, sedangkan perkataannya berasal dari Imam Tirmidzi.}

$$
\begin{aligned}
& \text { وروي مسام و الترمذي, و اللفظ له, عن سفيان بن } \\
& \text { عبد الله الثقفي رضي الله عنه قال: قلت يارسول الله } \\
& \text { حدثني بأمر أعتصم به, قال: قل: ربي الله, ثم } \\
& \text { استقم. قلت: يا رسول الله صلي الله صلي الله عليه } \\
& \text { وسلم ما أخوف ما تخاف عليّ؟ فأخذ رسول الله } \\
& \text { صلي الله عليه و سلم بلسان نفسه ثم قال: هذا28 }
\end{aligned}
$$

${ }^{28}$ Imam Tirmidzi, No. Hadis: 2410, 210. Ditakhrij oleh al-Tayalisi: 1231; Imam Ahmad bin Hanbal: 3/413; Imam al-Darimi: 2714; Imam Ibnu Majah: 3972; Ibnu Abi Dunya dalam al-Sumtu. 6; Imam Ibnu Hibban: 5699, 5700; Imam alThabarani dalam al-Kabïr: 6396, 6397; Imam alHakim: 4/313; Imam al-Khatib al-Baghdadi: 11/78; Imam al-Baihaqi dalam bab Adāb: 394; al-Mizzi dalam Tahzib al-Kamāl: 25/629; Tuhfat al-Asyrāf. 4/20, hadis: 4478; al-Musnad al-Jami': 7/43, hadis: 4832; Sahih al-Tirmidzi li Albani: 1965; Imam Muslim: 1/47; min Thariq al-'Aurah, dari Sufyan
Artinya:

Diriwayatkan oleh Imam Muslim dan Imam Tirmidzi, dan lafadznya dari Imam Tirmidzi, dari Sufyan bin 'Abdullah al-Tsaqafi radhiya Allahu 'anhu, ia berkata: Aku bekata kepada Rasulullah shallahu 'alaihi wa sallam, tolong katakana kepadaku tentang perkara yang membuatku merasa terlindungi dengannya, maka Rasulullah saw menjawab: katakanlah "Rabbiya Allah" (Tuhanku Allah) dan istiqamahlah (konsisten). Lalu aku kembali bertanya: Ya Rasulallah saw, apakah sesuatu yang paling ditakuti, sesuatu yang engkau takuti dari diriku? Kemudian Rasul saw memegang lidahnya, lalu mengatakan ini.

g. Pengajaran Rasulullah saw diawali dengan sebuah statement tanpa soal

Sebagai seorang guru, Rasulullah saw tidak mengajarkan kepada para sahabat beliau dengan menggunakan satu atau dua metode, beliau mempunyai banyak alternatif sehingga para sabahat ketika tidak memahami dengan penjelasan dari Rasul saw, maka beliau akan memperjelasnya dengan cara yang mudah dipahami oleh sahabat. Salah satu metode yang beliau gunakan adalah, diawalinya pengajaran dengan cara memberikan statement, atau cara agar para sahabat dapat menjawab segala bentuk tuduhan-tuduhan yang

bin Abdillah dari Ayahnya; Lihat al-Musnad alJami`: 7/42, hadis: 4830. 
menyudutkan ajaran yang beliau ajarkan.

Salah satu hadis yang akan dikutip mengenai metode pembelajaran Rasulullah yaitu, hadis yang diriwayatkan oleh Imam Bukhari dan Imam Muslim.

$$
\begin{aligned}
& \text { روي البخاري ومسام عن أبي هريرة رضي الله }
\end{aligned}
$$

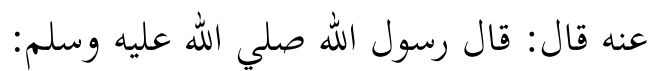

$$
\begin{aligned}
& \text { يأتي الشيطان أحدكم , فيقول: من خلق كذا } \\
& \text { وكذا؟ حتي يقول له: من خلق ربك؟ قإذا بلغ } \\
& \text { ذلك, فليستعذ بالله ولينته } 29
\end{aligned}
$$

Artinya:

Diriwayatkan oleh Imam Bukhari dan Imam Muslim dari Abu Hurairah radhiya Allahu 'anhu ia berkata: Rasulullah shallahu 'alaihi wa sallam bersabda: suatu ketika syaitan datang kepada kalian, kemudian ia mengatakan, siapa yang menciptakan ini dan itu? hingga dia mengatakan baginya, siapa yang menciptakan Tuhanmu? Maka apabila sampai pada pertanyaan tersebut pintalah perlindungan kepada Tuhanmu (Allah swt) dan selesai.

Pada hadis kedua, diriwayatkan oleh Imam Muslim, Imam Abu Daud dan Imam Nasāi

$$
\text { ؤي رواية عند مسلم و أبي داود و النسائي عن هريرة قال }
$$

29 Imam Bukhari, al-Jami 'al-Sahịh: alMusnad min Hadith al-Rasulillah Shallallāhu 'alaihi wa Sallam wa Sunanihi wa Ayyāmihi li Abī Abdillah Muhammad bin Ismail al-Bukhāri, 6: 24, di dalam kitab permulaan penciptaan (Bab, Sifat Iblis dan para prajuritnya), (Kairo: Mathba'ah Salafiyyah wa Maktabatuna $1400 \mathrm{H}$ ).

$$
\begin{aligned}
& \text { هذا: خلق الله الخلق, فمن خلق الله فمن وجد } \\
& \text { من ذلك شيئا, فليقل: امنت بالله. وفي رواية } \\
& \text { ثانية: فإذا قالوا ذلك, فقولوا: الله أحد, الله } \\
& \text { الصمد, لمج يلد, ولم يولد, لم يكن له كفوا }
\end{aligned}
$$

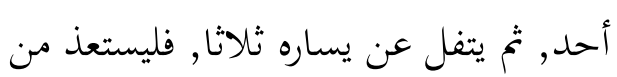

$$
\begin{aligned}
& \text { الشيطان }
\end{aligned}
$$

Artinya:

Diriwayatkan oleh Imam Muslim, Imam Abu Daud dan Imam Nasai dari Abu Hurairah ia berkata: Rasulullah shallahu 'alaihi wa sallam bersabda: Masihkah manusia saling bertanya, hingga dikatakan seperti ini: Allah menciptakaan makhluk, dan siapa yang menciptakan Allah? Maka barang siapa yang menemukan sesuatu dari itu, katakanlah: aku beriman kepada Allah. Pada riwayat kedua: Apabila telah dikatakan seperti itu, katakanlah: Allah itu Esa, Allah adalah Tuhan tempat bergantung segala sesuatu, tidak melahirkan, tidak pula dilahirkan, kemudian ludahlah ke kiri sebanyak tiga kali, dan mintalah perlindungan dari godaan syaitan.

h. Rasulullah saw Menjawab pertanyaan yang bertanya tentang apa yang ditanyakan

Setiap pengajaran Nabi Muhammad saw, selalu bernilai syariat dan hukum demi kepentingan agama pada saat itu serta untuk umatnya setelah beliau wafat. Beliau mengajarkan ilmu dan pengetahuan agama dengan bermacam-macam

\footnotetext{
${ }^{30}$ Imam Nasa'i di dalam al-Kubra, Sunan
} al-Nasā'i, 6: 169, kitab pekerjaan sehari semalam, (Bab, al-Waswasah), (Riyadh: Maktabah alMa'arif li al-Nashr wa al-Tauzi' 1417 H). 
metode, berikutnya adalah dengan cara menjawaban pertanyaan para sahabat yang bertanya sesuai dengan apa yang ditanyakan. Baik berupa aturan-aturan agama, nasehat-nasehat bagi para sahabat Nabi saw yang bertanya berkenaan dengan sesuatu yang akan musnah maupun yang telah hilang dari pengetahuan yang diperlukan oleh penanya tentang ajaran agama.

Berkenaan dengan metode ini, akan dikutip dari hadis diriwayatkan oleh Imam Muslim dan Imam Abu Daud dari sahabat Ibnu Abbas r.a.

$$
\begin{aligned}
& \text { روي مسام و أبي داود, و اللفظ له, عن ابن } \\
& \text { عباس رضي الله عنهما قال: بعث رسول الله } \\
& \text { صلي الله عليه وسلم فلانا الأسلمي, بعث معه } \\
& \text { بثمان عشرة بدنة, فقال - الأسلمي لرسول الله } \\
& \text { صلي الله عليه وسلم- : أريت إن أزحف عليّ } \\
& \text { منها شيء؟, قال: تنحروها ثم تصبغ نعلها في } \\
& \text { دمها, ثم اضربها علي صفحتها, ولا تأكل منها } \\
& \text { أنت ولا أحد من أهل رفقتك } 31
\end{aligned}
$$

Artinya:

diriwayatkan oleh Imam Muslim dan Imam abu Daud, dan lafadznya dari Imam Abu Daud, dari Ibnu Abbas radhiya Allahu 'anhuma, ia berkata: Rasulullah shallahu 'alaihi wa sallam mengutus seorang al-Aslami, bersamanya Rasul saw mengutus

${ }^{31}$ Imam Muslim, Sahih Muslim, 9: 77, di dalam kitab Haji, (Bab, Apa yang perlu dilakukan dengan Hadyi apabila rusak di jalan), (Riyadh: Bait al-Afkar al-Dauliyyah li al-Nashr wa al-Tauzi' 1997). delapan belas unta, maka al-Aslami berkata kepada Rasulullah saw: Apakah engkau telah melihat bahwa aku dirayap oleh unta itu? Rasul saw berkata: sembelihlah ia, kemudian warnai daerah kaki di darahnya, kemudian pukul ia, dan jangan engkau makan darinya, dan tidak seorang pun dari rombonganmu.

\section{KESIMPULAN}

Metode dakwah Rasulullah dalam menerapkan pengajaran kepada para sahabat memberikan dampak besar terhadap perkembangan karakter sahabat dalam meneruskan langkah dakwah Nabi.

Dari beberapa metode dakwah yang disampaikan Nabi, hampir semua terdokumentasi dalam kitab-kitab hadis terutama dalam kitab hadis kutub sittah dan beberapa kitab hadis yang lain. Jika melihat perkembangan metode dakwah yang diajarkan kepada para sahabat belum banyak ditemukannya teori-teori pembelajaran seperti saat ini. Hal ini menunjukkan Nabi telah mempraktekkan nilai-nilai dakwah melalui pengajaran. Dakwah yang diajarkan kepada para sahabat terbukti menghasilkan didikan yang berkarakter kuat, mencetak figur penting para sahabat dengan karekter yang dapat diterapan pada setiap pengajaran yang disampaikan Nabi.

\section{DAFTAR PUSTAKA}

Abu Ghuddah, 'Abd Fattah. (2008). alRasūl al-Mu'allim wa Asātibuhu fì 
al-Ta'Tim. Beirut: Dār al-Bashāir alIslamiyah.

Bukhari. (1980). Al-Jami' al-Sahih: alMusnad min Hadith al-Rasulillah Shallallahu 'alaihi wa Sallam wa Sunanihi wa Ayyamihi li Abi Abdillah Muhammad in Ismail alBukhari. Kairo: Mathba'ah Salafiyyah wa Maktabatuna.

Buthi, Said Ramadhan. (1977). Fiqh alSirah; Dirasat Manhajiyah 'ilmiyah li Sirat al-Mustafa 'alaihi al-Salah wa al-Salam wa ma yantawi 'alaihi min 'izat wa Mabadi' wa Ahkam. Damaskus: Dar al-Fikr.

Effendi, Mochtar. (2002). Bangunan Masyarakat Islam. Palembang: Penerbit Universitas Sriwijaya bekerja sama dengan Yayasan Pendidikan dan Ilmu islam "AlMukhtar.

Hodgson, M. G. (2009). The venture of Islam, Volume 1: the classical age of Islam. University of Chicago press. , The Venture of Islam. (2002). Islam dan Sejarah dalam Peradaban Dunia. Jakarta, Paramadina.

Ibnu Majah, Ibnu. Sunan al-Hafidz Abi 'Abdillah Muhammad bin Yazid alQazwiny Ibnu Majah, di-tahqiq oleh Muhammad Fuad 'Abdul Baqi, (Matba'ah Dar al-Ihya al-Kutub al'Arabiyyah).

Khan, A M. dan Dian Andayani. (2013). Pendidikan Karakter Perspektif Islam. Bandung: PT Remaja Rosda.

Munawwar, Said A. H. (2014) disampaikan ketika mata kuliah alSirah al-Nabawiyah.

Muslim. (1997). Sahih Muslim. Riyadh: Bait al-Afkar al-Dauliyyah li alNashr wa al-Tauzi'.

Nasa'i. (1997). Sunan al-Nasa'i. Riyadh: Maktabah al-Ma'arif li al-Nashr wa al-Tauzi'.
Nata, Abudin. (1997) Konsep Pendidikan Ibn Sina. Jakarta, Disertasi Institut Agama Islam Negeri Syarif Hidayatullah.

Nawawi, Hadari. (2003). Metode Penelitian Bidang Sosial. Yogyakarta: Gajah Mada University Press.

Poeradisastra, S.I. (2008). Sumbangan Islam kepada Ilmu dan Peradaban Modern. Jakarta: Komunitas Bambu.

Ramly, Najmuddin. (2005). Membangun Pendidikan yang Memberdayakan dan Mencerahkan: Teologi Humanisme, Fondasi pendidikan di Tengah Perubahan. Jakarta: Penerbit Grafindo Khazanah Ilmu.

Sallabi, Ali M. (2005). al-Sirah alNabawiyah; 'Ardu Waqā'i wa Tahlilu Ahdath. Kairo: Muassasah Iqra'.

Tirmidzi. (1996). Al-Jami' al-Kabir li alImam al-Hafidz Abi Isa Muhammad bin Isa al-Tirmidzi, di-tahqiq oleh Bahar 'Awad Ma'ruf. Dar al-Gharb al-Islamy. 